\title{
Molecular characterization of the malaria vector Anopheles barbirostris van der Wulp in Sri Lanka
}

\author{
Kanapathy Gajapathy ${ }^{1 *}$, Pavilupillai J Jude , Sara L Goodacre², Lalanthika BS Peiris ${ }^{3}$, Ranjan Ramasamy ${ }^{1}$ \\ and Sinnathamby N Surendran ${ }^{1^{*}}$
}

\begin{abstract}
Background: Anopheles barbirostris is a vector of malaria in Sri Lanka. The taxon exists as a species complex in the Southeast Asian region. Previous studies using molecular markers suggest that there are more than 4 distinct clades within the An. barbirostris complex in Southeast Asia. The present study characterizes Sri Lankan An. barbirostris using mtDNA cytochrome oxidase subunit I (COI) and ribosomal RNA internal transcribed spacer 2 (ITS2) gene sequences.
\end{abstract}

Findings: DNA was extracted from morphologically identified An. barbirostris specimens from Sri Lanka, the COI and ITS2 regions amplified and their sequences analysed by comparison with other GenBank entries. Maximum likelihood trees suggested that Sri Lankan An. barbirostris constitute a different molecular type most closely related to clade I.

Conclusions: Considering the uncorrected $p$ distances between the clade I and Sri Lankan specimens it is fair to assume that the specimens collected from widely separated locations in Sri Lanka with morphology characteristic of An. barbirostris s.l. form a new molecular type with close resemblance to An. barbirostris s.s from Indonesia and Thailand.

Keywords: Anopheles barbirostris, Malaria vector, Species complex, Sri Lanka

\section{Background}

Anopheles barbirostris van der Wulp is a vector of malaria in Sri Lanka [1], India and Southeast Asia, and a vector of Brugian filariasis in Southeast Asia [2]. Anopheles barbirostris and 12 related species form the taxonomically complex Barbirostris Group of malaria vectors in this region ([3] and references therein). An. barbirostris s.l. is a species complex with up to five sibling species whose individual distributions are not well established [4-7]. Members of this complex are typically zoophillic, develop in still or slow moving fresh water such as in swamps and rice fields, and are relatively tolerant of organic pollution ([3] and references therein). Larvae were recently also found in brackish water (salinity of 4-15 parts per thousand) in domestic wells and mangrove swamps in the Jaffna district of Northern Sri Lanka [8]. Morphological differentiation of anopheline sibling species

\footnotetext{
* Correspondence: gayan156@gmail.com; noble@jfn.ac.lk

'Department of Zoology, Faculty of Science, University of Jaffna, Jaffna

40000, Sri Lanka

Full list of author information is available at the end of the article
}

is difficult and has previously led to significant misidentification with implications for vector control, e.g. mosquitoes long identified morphologically as Anopheles subpictus sibling species B in Sri Lanka were recently shown to be Anopheles sundaicus s.l. by analysis of ribosomal RNA gene sequences [9].

Other members of the Barbirostris Group, e.g. An. reidi and $A n$. barbrumbosus, have been identified in Sri Lanka [10] but the five other species of the Barbirostris Subgroup, viz. An. campestris, An. donaldi, An. franciscoi, An. hodgkini and An. pollicaris [11] have not been reported in Sri Lanka. The present study was designed to characterize morphologically identified An. barbirostris s.l. in Sri Lanka using DNA sequences of the cytochrome oxidase subunit I (COI) of mtDNA and internal transcribed spacer 2 (ITS2) of ribosomal RNA in relation to previous DNA sequence data from An. barbirostris s.l. collected elsewhere in Southeast Asia [6]. 


\section{Methods}

\section{Mosquito collection}

Anopheline mosquitoes were collected from the widely separated locations of Hambantota, Nainadeevu and Puttalam in Sri Lanka (Figure 1) from January to July, 2012 using cattle baited traps. Mosquitoes were identified based on their morphology using taxonomic keys created for Sri Lankan anopheline mosquitoes [12].

\section{DNA extraction and PCR amplification of COI and ITS2 regions}

Among 27 morphologically identified An. barbirostris $s$. $l$., DNA was extracted from two, one and two specimens collected from Hambantota, Nainadeevu and Puttalam respectively using previously reported methods [13]. The COI region was PCR amplified with forward 5' TTG ATT TTT TGG TCA TCC AGA AGT 3' and reverse 5' TAG AGC TTA AAT TCA TTG CAC TAA TC 3' primers [6]. Each PCR (50 $\mu \mathrm{L}$ total volume) reaction mixture contained $1 \mathrm{x}$ Thermo Scientific Ready Mix (1.5 mM Mg Cl $2,0.625 \mathrm{U}$ Taq DNA polymerase, $0.2 \mathrm{mM}$ dNTPs and 1x Taq buffer), 2-4 $\mu$ l of template DNA and 10 pmoles of each primer. The thermal profile for PCR was $94^{\circ} \mathrm{C}$ for $5 \mathrm{~min}$, followed by 35 cycles of $95^{\circ} \mathrm{C}$ for

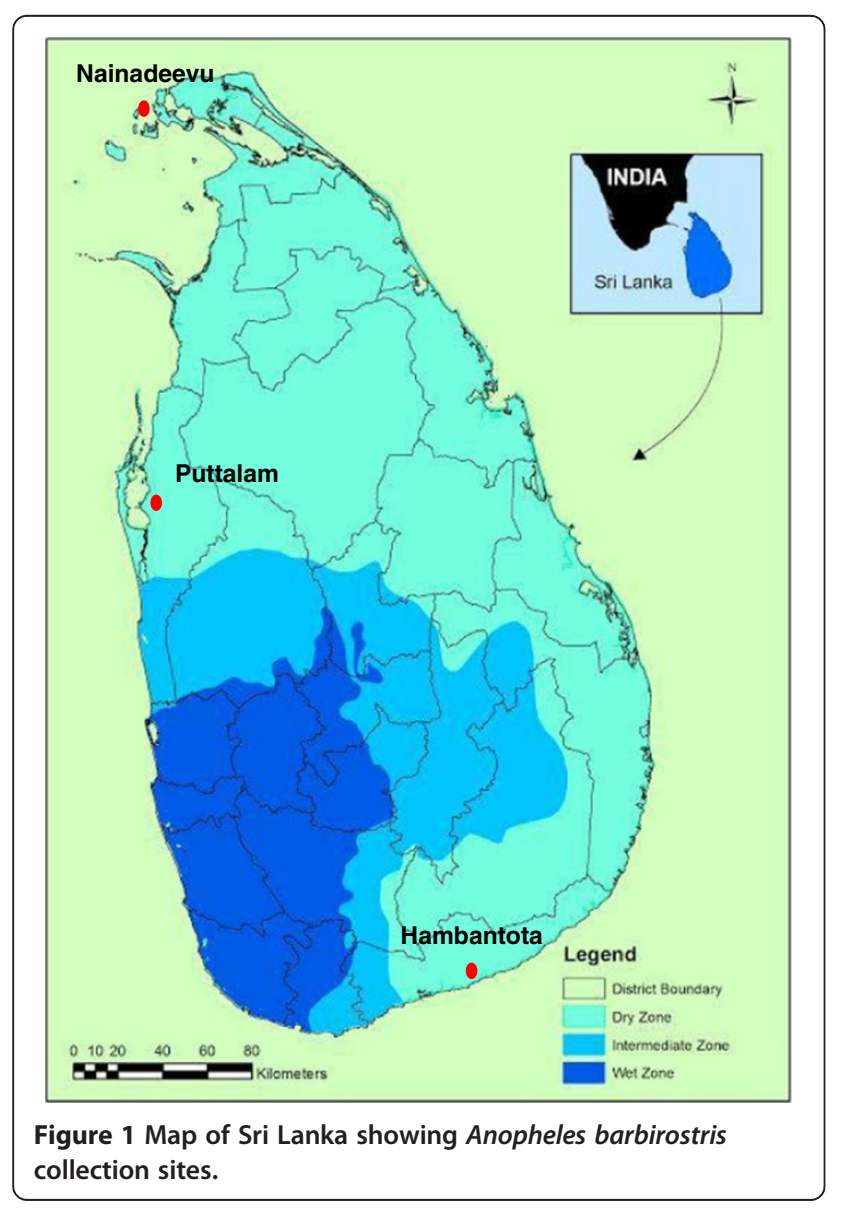

$40 \mathrm{~s}, 50^{\circ} \mathrm{C}$ for $1 \mathrm{~min}$ and $72^{\circ} \mathrm{C}$ for $1 \mathrm{~min}$. A final extension temperature of $72^{\circ} \mathrm{C}$ was set for $10 \mathrm{~min}$.

The ITS2 region was amplified using forward 5' ATC ACT CGG CTC ATG GAT CG 3' and reverse 5' ATG CTT AAA TTT AGG GGG TAG TC 3' primers [6]. Fifty $\mu \mathrm{l}$ reaction volumes were prepared with $1 \mathrm{x}$ reaction buffer, $2.5 \mathrm{mM} \mathrm{MgCl} 2$; $0.2 \mathrm{mM}$ dNTPs, 20pmoles of each primer, 1.0 $\mathrm{U}$ of Taq polymerase and $5 \mu \mathrm{l}$ of template DNA. The PCR thermal profile was $94^{\circ} \mathrm{C}$ for $5 \mathrm{~min}$, followed by 35 cycles of $94^{\circ} \mathrm{C}$ for $1 \mathrm{~min}, 55^{\circ} \mathrm{C}$ for $2 \mathrm{~min}, 72^{\circ} \mathrm{C}$ for $2 \mathrm{~min}$ and a final extension at $72^{\circ} \mathrm{C}$ for $10 \mathrm{~min}$. The amplified products were separated by agarose gel electrophoresis, stained with ethidium bromide and sequenced at Macrogen, Amsterdam, Netherlands.

Sequences were edited in Finch TV (Geospiza, Seattle, USA) and aligned with Clustal W (MEGA 5.1) [14]. A phylogenetic tree of the sequences was created using the maximum likelihood approach (Phyml 3.0) [15]. A HKY substitution model was selected with a gamma distribution based on the lower Bayesian criterion index (MEGA 5.1) [14]. Genbank deposited sequences from Thailand (16 for COI and 28 for ITS2) and Indonesia (08 samples for COI and 06 samples for ITS2) were also used in the tree construction $[5,6]$.

\section{Findings}

Anopheles barbirostris specimens were identified based on standard morphological characteristics [12]. The presence of a median tuft was observed in all flies. Median scales in the abdominal sternum were also observed. Maxillary palps were dark-scaled and the wings had a narrow apical fringe spot at the vein $R_{4+5}$.

All the chromatograms were clean and the ambiguous ends were removed before sequence analysis. The phylogenetic tree (Figure 2) constructed with $400 \mathrm{bp}$ of COI sequence data, including those from previously published sequences, confirmed that all five sequenced Sri Lankan specimens were members of the Barbirostris Complex. Sri Lankan specimens formed a sister clade to clade I of Paredes-Esquivel et al. [6], which is An. barbirostris s.s. Compared to sequences from the most closely related clade I, the Sri Lankan specimens showed $5.1 \%$ variation (with 20 variable sites) in the COI sequences. All the mutations were silent except two where tyrosine was replaced by serine and alanine replaced by proline. Intra-specific variations (0.4\%), not associated with specific location, were observed among the Sri Lankan COI sequences.

The maximum likelihood tree (Figure 3) created with 580 bp of ITS 2 sequence data varied slightly from the COI tree but the Sri Lankan specimens remained most closely related to clade I. Compared to sequences from the most closely related clade I, the Sri Lankan specimens showed $5.4 \%$ variation (with 28 variable sites 


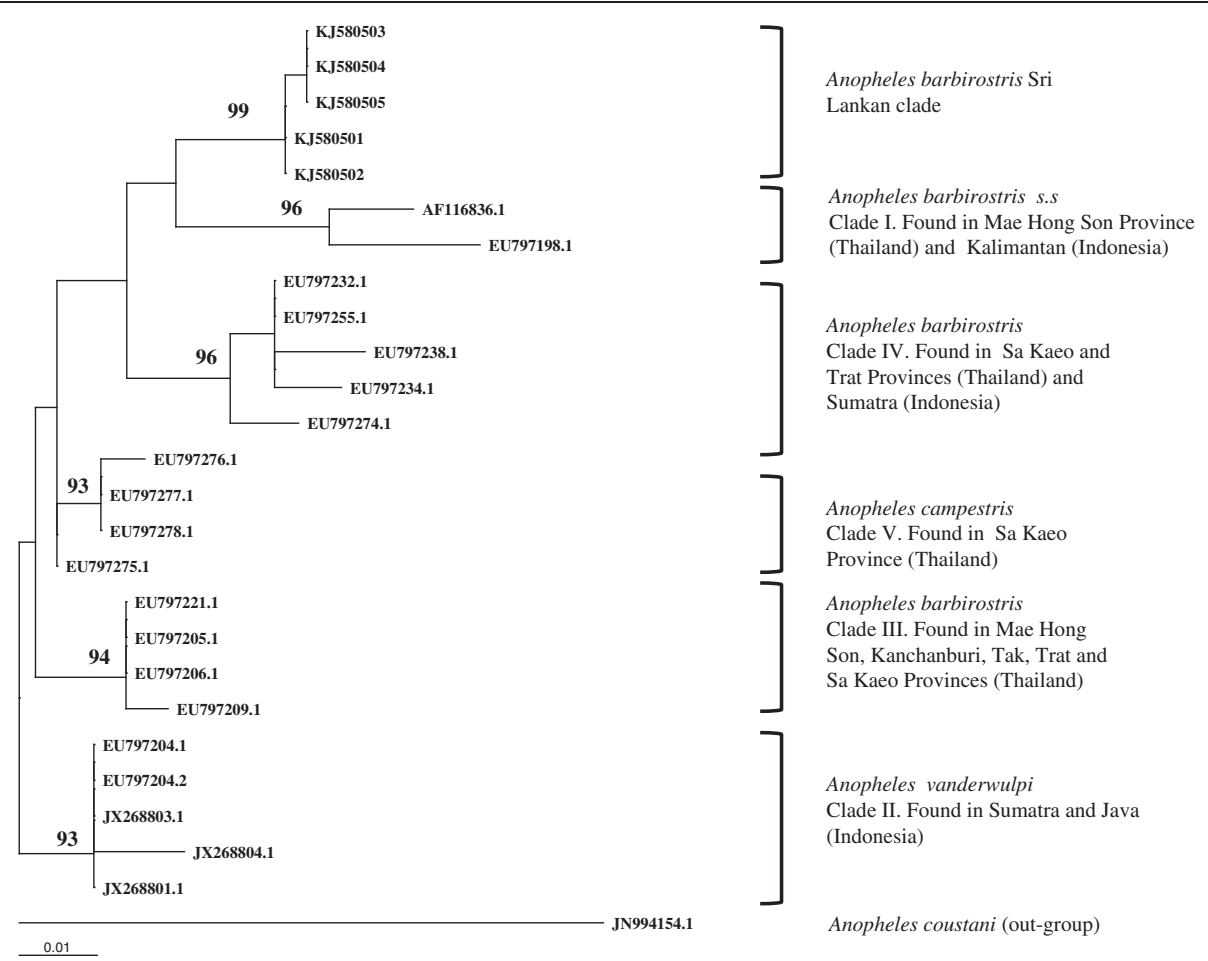

Figure 2 Maximum Likelihood tree created from CO1 sequence data (400 bp) using Phyml [15] with the HKY + G + I substitution

model. The nodes are shown with their bootstrap values; An. coustani was used as the out-group. The Genbank accession numbers for Sri Lankan samples are KJ580501 - KJ580505.

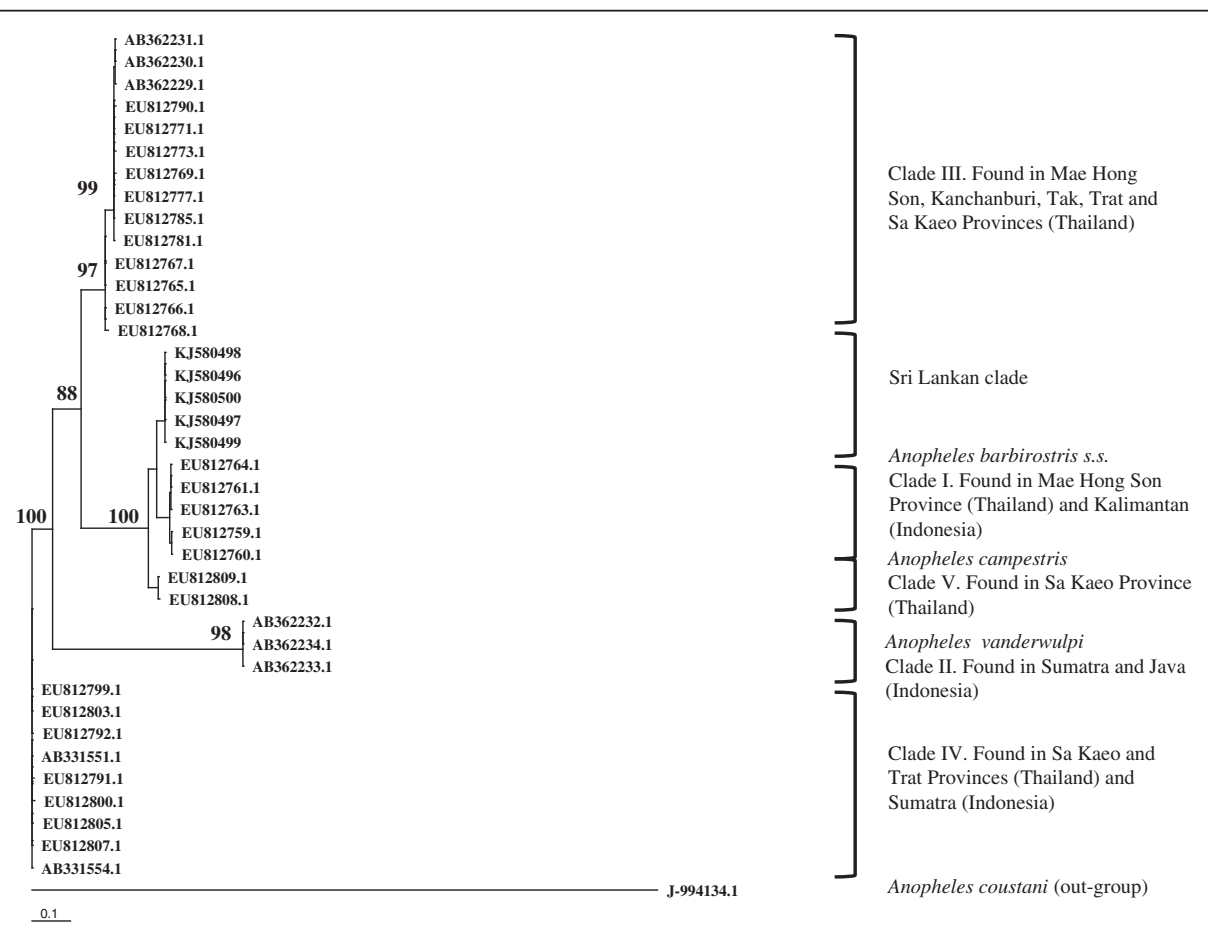

Figure 3 Maximum likelihood tree created from ITS2 sequence data (580 bp) using Phyml [15] with the HKY + G + I substitution model. The nodes are shown with their bootstrap values; An. coustani was used as the out-group. The GenBank accession numbers for Sri Lankan samples are KJ580496 - KJ580500. 
including 6 indels). The ITS2 sequences from all five Sri Lankan specimens were identical.

All the nodes in both trees (Figures 2 and 3) were well supported with strong bootstrap values. The maximum likelihood trees created with $\mathrm{HKY}+\mathrm{G}+\mathrm{I}$ model in Phyml were in agreement with the Bayesian trees (data not shown).

Anopheles barbirostris were previously classified into five distinct clades by Paredes-Esquivel et al. [6], based on COI and ITS2 data. Clade IV was identified as a species with intermediate morphology between An. barbirostris and An. campestris. Later, clade I was identified unequivocally as $A n$. barbirostris s.s. and Clade II was described as a new species named $A n$. vanderwulpi [16]. Saeung et al. [5] recognized three sibling species in the $A n$. barbirostris complex based on karyotyping and COI, COII and ITS2 sequences. The sibling species designated A1 and A2 by Saeung et al. [5] correspond to clades III and IV, respectively, of Paredes-Esquivel et al. [6]. Differential susceptibility of the members of the Barbirostris Complex to infection with malaria parasites has been established in laboratory reared colonies in Thailand [17].

The disparity between mitochondrial (COI) and nuclear gene (ITS2) trees in the present analysis may be explained in part by different evolutionary rates. Mitochondrial DNA typically mutates at a higher rate than nuclear sequences [18] such as the ITS2, and thus the latter may be more appropriate for analysing relationships between species.

\section{Conclusions}

Considering the uncorrected $\mathrm{p}$ distances of $4.5 \%$ (COI) and 5.1\% (ITS2) between the clade I and Sri Lankan specimens it is fair to assume that the specimens collected from widely separated locations in Sri Lanka with morphology characteristic of An. barbirostris s.l. form a new molecular type with close resemblance to the clade I (An. barbirostris s.s) of Paredes-Esquivel et al. [6].

\section{Competing interests}

The authors declare that they have no competing interests.

\section{Authors' contributions}

SNS, KG and RR designed the study, PJJ and LBSP did field collection and sample identification. KG, SG and SNS did laboratory studies and analysis. KG, SNS and RR wrote the manuscript. SG contributed to the content of the manuscript. All authors read and approved the final version of the manuscript.

\section{Acknowledgements}

The authors acknowledge the Director, National Anti-malaria Campaign, Sri Lanka for permission to collect mosquitoes and members of the Entomology Team of the Anti-Malaria Campaign of the district of Hambantota for field assistance. The study was partly supported by grant NSF/RG/BT/2011/04 from the National Science Foundation of Sri Lanka.

\section{Author details}

'Department of Zoology, Faculty of Science, University of Jaffna, Jaffna 40000, Sri Lanka. ${ }^{2}$ School of Life Sciences, University of Nottingham, Nottingham NG7 2RD, UK. ${ }^{3}$ Regional Office, Anti Malaria Campaign, Hambantota 82000, Sri Lanka.

Received: 10 April 2014 Accepted: 2 July 2014

Published: 29 July 2014

\section{References}

1. Amerasinghe PH, Amerasinghe FP, Kondarsen FFP, Fonseka KT, Wirtz RA: Malaria vectors in a traditional dry zone village in Sri Lanka. Am J Trop Med Hyg 1999, 60(3):421-429.

2. Lien JC, Kawengian BA, Partono F, Lami B, Cross JH: A brief survey of the mosquitoes of South Sulawesi, Indonesia, with special reference to the identity of Anopheles barbirostris (Diptera: Culicidae) from the Margolembo area. J Med Entomol 1977, 13:719-727.

3. Sinka ME, Bangs MJ, Manguin S, Chareonviriyaphap T, Patil AP, Temperley WH, Gething PW, Elyazarn IRF, Kabaria CW, Harbach RE, Hay SI: The dominant Anopheles vectors of human malaria in the Asia-Pacific region: occurrence data, distribution maps and bionomic précis. Parasit Vectors 2011, 4:8.

4. Saeung A, Otsuka Y, Baimai V, Somboon P, Pitaswat B, Tuetun B, Junkum A, Takaoka H, Choochote W: Cytogenetic and molecular evidence for two species in the Anopheles barbirostris complex (Diptera: Culicidae) in Thailand. Parasitol Res 2007, 101:1337-1344.

5. Saeung A, Baimai V, Otsuka Y, Rattanarithikul R, Somboon P, Junkum A, Tuetun B, Takaoka H, Choochote W: Molecular and cytogenetic evidence of three sibling species of the Anopheles barbirostris Form A (Diptera: Culicidae) in Thailand. Parasitol Res 2008, 102:499-507.

6. Paredes-Esquivel C, Donnelly MJ, Harbach RE, Townson H: A molecular phylogeny of mosquitoes in the Anopheles barbirostris subgroup reveals cryptic species: implications for identification of disease vectors. Mol Phylogenet Evol 2009, 50(1):141-151.

7. Jariyapan N, Baimai V, Poovorawan Y, Roytrakul S, Saeung A, Thongsahuan S, Suwannamit S, Otsuka Y, Choochote W: Analysis of female salaivary gland proteins of the Anopheles barbirostris complex (Diptera: Culicidae) in Thailand. Parasitol Res 2010, 107:509-516.

8. Jude PJ, Tharmatha T, Gopika S, Meena S, Kannathasan S, Raveendran S, Ramasamy R, Surendran SN: Salinity-tolerant larvae of mosquito vectors in the tropical coast of Jaffna. Sri Lanka and the effect of salinity on the toxicity of Bacillus thuringiensis to Aedes aegypti larvae. Parasit Vectors 2012, 5:269

9. Surendran SN, Singh OP, Jude PJ, Ramasamy R: Genetic evidence for malaria vectors of the Anopheles sundaicus complex in Sri Lanka with morphological characteristics attributed to Anopheles subpictus species B. Malar J 2010, 9:343.

10. Harrison BA, Reinert JF, Sirivanakarn S, Huang YM, Peyton EL, de Meillon B: Distributional and biological notes on mosquitoes from Sri Lanka (Ceylon) (Diptera: Culicidae). Mosa Syst 1974, 6:142-162.

11. Reid JA: The Anopheles barbirostris group (Diptera, Culicidae). Bull Entomol Res 1962, 53(1):1-57.

12. Amerasinghe FP: A guide to the identification of the anopheline mosquitoes (Diptera: Culicidae) of Sri Lanka. Cey J Sci (Biol Sci) 1992, 22:1-13.

13. Gajapathy K, Peiris LBS, Goodacre SL, Silva A, Jude PJ, Surendran SN: Molecular identification of potential leishmaniasis vector species within the Phlebotomus (Euphlebotomus) argentipes species complex in Sri Lanka. Parasit Vectors 2013, 6:302.

14. Tamura K, Peterson D, Peterson N, Stecher G, Nei M, Kumar S: MEGA5: Molecular evolutionary genetics analysis using maximum likelihood, evolutionary distance, and maximum parsimony method. Mol Biol Evol 2011, 28:2731-2739.

15. Guindon S, Gascuel O: A simple, fast and accurate algorithm to estimate large phylogenies by maximum likelihood. Syst Biol 2008, 52:696-704

16. Townson H, Dyer N, McAlister E, Satoto TBT, Boewono DT, Bangs MJ, Harbach RE: Systematics of Anopheles barbirostris van der Wulp and a sibling species of the Barbirostris Complex (Diptera: Culicidae) in eastern Java, Indonesia. Syst Entomol 2013, 38:180-191. 
17. Thongsahuan S, Baimai V, Junkum A, Saeung A, Min GS, Joshi D, Park MH, Somboon P, Suwonkerd W, Tippawangkosol P, Jariyapan N, Choochote W: Susceptibility of Anopheles campestris-like and Anopheles barbirostris species complexes to Plasmodium falciparum and Plasmodium vivax in Thailand. Mem Inst Oswaldo Cruz 2011, 106:105-112.

18. Brown WM, George M, Wilson AC: Rapid evolution of animal mitochondrial DNA. Genetics 1979, 76:1967-1971.

doi:10.1186/1756-3305-7-348

Cite this article as: Gajapathy et al:: Molecular characterization of the

malaria vector Anopheles barbirostris van der Wulp in Sri Lanka. Parasites \& Vectors 2014 7:348.

\section{Submit your next manuscript to BioMed Central and take full advantage of:}

- Convenient online submission

- Thorough peer review

- No space constraints or color figure charges

- Immediate publication on acceptance

- Inclusion in PubMed, CAS, Scopus and Google Scholar

- Research which is freely available for redistribution 